\title{
MCF Material as an Attractive Support for Vanadium Oxide Applied as a Catalyst for Propene Epoxidation with $\mathrm{N}_{2} \mathrm{O}$
}

\author{
Agnieszka Held ${ }^{1} \cdot$ Jolanta Kowalska-Kuś ${ }^{1} \cdot K_{\text {Krystyna Nowińska }}{ }^{*}$ Kinga Góra-Marek $^{2}$
}

Received: 3 January 2018 / Accepted: 15 May 2018 / Published online: 23 May 2018

(c) The Author(s) 2018

\begin{abstract}
Vanadium modified mesocellular silica foams (MCF) materials (V content ca. 3 and 5 wt\%) prepared by the impregnation method show mainly isolated or low-polymeric $\mathrm{VO}_{\mathrm{x}}$ species, which was confirmed by means of Raman spectroscopy and DR UV-Vis. Textural measurements, and also XRD and TEM results indicate that the characteristic mesocellular structural features of MCFs are preserved after vanadium incorporation. The MCF-supported vanadia catalysts exhibit much higher propene conversion and propene oxide productivity when compared to vanadium modified mesoporous silicas of 2D structure, demonstrating that apart from the presence of highly dispersed isolated vanadium species, internal molecular transport within three-dimensional ultra large pores of MCF materials also plays an important role in gas-phase propene epoxidation.
\end{abstract}

\section{Graphical Abstract}

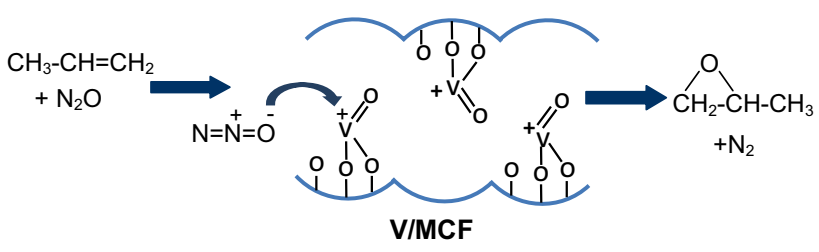

Keywords Epoxidation - Supported vanadia catalyst $\cdot$ Mesocellular silica foam $\cdot$ Propene $\cdot$ Propene oxide $\cdot$ Nitrous oxide

\section{Introduction}

Propene oxide (PO), applied for polyurethane synthesis and for the production of many other consumer goods, belongs to the most important organic intermediates the demand for which is continually increasing $[1,2]$. PO is produced by two major technologies: the chlorohydrin process and the process based on organic hydroperoxide application [3].

Electronic supplementary material The online version of this article (https://doi.org/10.1007/s10562-018-2420-6) contains supplementary material, which is available to authorized users.

Agnieszka Held

awaclaw@amu.edu.pl

1 Faculty of Chemistry, Adam Mickiewicz University, Umultowska 89b, 61-614 Poznań, Poland

2 Faculty of Chemistry, Jagiellonian University in Kraków, Gronostajowa 2, 30-387 Kraków, Poland
These processes are complex, expensive and not environmentally friendly. Therefore, the search for a method of direct propene epoxidation in a gas phase is one of the most desirable and challenging goals of PO production. Considering this, molecular oxygen would be the most desirable oxidant for propene epoxidation because of its availability and low price. However, direct propene with oxygen oxidation brings about a mainly unselective process. Nevertheless, silica supported ruthenium-copper based catalyst modified with alkaline ions indicated relatively high PO yields when oxygen was used for propene oxidation [3]. Furthermore, utilization of hydrogen peroxide synthesised in situ from a hydrogen and oxygen mixture as an oxidant has been commercialized [4].

Another indirect source of oxygen may be treated nitrous oxide found to be an alternative oxidant for different hydrocarbon oxidation performed in the presence of various catalysts $[5,6]$. Application of nitrous oxide for direct propane 
and propene oxidation performed over iron modified silicas evidenced the usefulness of that oxidant for propane oxydehydrogenation $(\mathrm{ODH})[7]$ as well as for propene epoxidation $[8,9]$. Iron modified zeolites have also been used for the new technology of benzene to phenol oxidation with nitrous oxide as an oxidant $[10,11]$. ODH of propane and ethylbenzene with nitrous oxide was performed not only over iron catalysts but also over vanadium catalysts and resulted in high selectivity towards propene or styrene, respectively [12, 13]. Taking into consideration the earlier effective application of vanadium catalysts with nitrous oxide for an oxidation reaction we have successfully applied this system for propene epoxidation $[14,15]$. Both propene conversion and selectivity to PO were influenced by the nature of the support and it appeared that silica brings about the best results for propene epoxidation [14]. It has been shown that high vanadium oxide dispersion results in the formation of isolated vanadium species in tetrahedral coordination which favours propene epoxidation.

Vanadium oxide supported on mesoporous silicas characterized with a 2D structure (SBA-3, SBA-15 and MCM41) shows a very high surface area and creates conditions for the formation of isolated vanadium species, catalytically active for PO formation. It seems, however, that product penetration along the channels of the $2 \mathrm{D}$ structure may be responsible for further $\mathrm{PO}$ oxidation and, as a consequence, in relatively high selectivity to $\mathrm{CO}_{\mathrm{x}}\left(\mathrm{CO}\right.$ and $\left.\mathrm{CO}_{2}\right)$.

Therefore, in the presented paper we report the development of the new efficient mesoporous V-containing MCF silica catalyst featuring a well-defined 3D, ultra-large mesopore structure that exhibits much higher propene oxide productivity than the previously studied V/silica systems. The influence of the nature of vanadium species on the catalytic performance of the $\mathrm{V}$-containing materials is discussed in the light of a detailed characterization of the physicochemical properties of the catalysts by low-temperature $\mathrm{N}_{2}$ adsorption/desorption isotherms, low-angle XRD, TEM, SEM, DR UV-Vis, Raman spectroscopy, and FT-IR spectra of adsorbed pyridine.

\section{Experimental}

\subsection{Catalyst Preparation}

Mesocellular silica foam (MCF) was used as a support for the vanadium oxide active phase. The synthesis of MCF was performed using a procedure described by Kuśtrowski et al. [16]. The following chemicals were used in the synthesis of the support: triblock copolymer, poly(ethylene glycol)block-poly(propylene glycol)-block-poly(ethylene glycol) (Aldrich) as a template, 1,3,5-trimethylbenzene (mesitylene, Aldrich) as the organic swelling agent, tetraethyl orthosilicate (TEOS, Aldrich, 98\%) as a source of silicon, hydrochloric acid (Chempur, 35-38\%), and $\mathrm{NH}_{4} \mathrm{~F}$ (POCh).

A total of $4.0 \mathrm{~g}$ of Pluronic P123 was dissolved in $150 \mathrm{~mL}$ of aqueous solution of $\mathrm{HCl}(1.6 \mathrm{M})$ at $313 \mathrm{~K}$. After $2 \mathrm{~h}$ of vigorous stirring, $\mathrm{NH}_{4} \mathrm{~F}(46.7 \mathrm{mg})$ and 1,3,5-trimethylbenzene (mesitylene, $2.0 \mathrm{~g}$ ) were added and stirred for $1 \mathrm{~h}$. Then, tetraethyl orthosilicate (TEOS, $9.14 \mathrm{~cm}^{3}$ ) was added. The obtained suspension was stirred for $20 \mathrm{~h}$ at $313 \mathrm{~K}$. Subsequently, the slurry was transferred to an autoclave and aged at $373 \mathrm{~K}$ for $24 \mathrm{~h}$. The obtained precipitate was filtered, washed with distilled water, and dried in air. In order to remove the template, the resulting solid was calcined at $823 \mathrm{~K}$ for $8 \mathrm{~h}$ with a heating rate of $1 \mathrm{~K} / \mathrm{min}$.

The supported catalysts were prepared by an impregnation technique using an aqueous solution of $\mathrm{VOSO}_{4}(97 \%$, Aldrich). The amount of vanadyl sulfate was adjusted to obtain a transition metal content in the catalysts equal to 3 and $5 \mathrm{wt} \%$. After drying at $373 \mathrm{~K}$ overnight, the obtained samples were calcined at $823 \mathrm{~K}$ in air under static conditions for $1 \mathrm{~h}$.

\subsection{Characterization Techniques}

As prepared non-modified mesoporous matrices and vanadium modified samples were characterized by powder X-ray diffraction (XRD) measurements performed on a Bruker AXS D8 Advance diffractometer, $\mathrm{CuK}_{\alpha}$ radiation $(\lambda=0.154 \mathrm{~nm})$ in the range of $2 \theta$ equal to $0.3^{\circ}-6^{\circ}$.

The textural parameters of the as-prepared non-modified mesoporous matrices and vanadium modified final catalysts were determined by $\mathrm{N}_{2}$ sorption at $77 \mathrm{~K}$ using a Quantachrome Nova 1000e sorptometer after outgassing the materials under vacuum at $573 \mathrm{~K}$ for $16 \mathrm{~h}$.

UV-Vis diffuse reflectance analysis was carried out on a Varian Cary 100 spectrophotometer. The UV-Vis spectra were recorded at room temperature (RT) using $\mathrm{BaSO}_{4}$ as a reference material. Diffuse reflectance spectra were taken in the range of $200-800 \mathrm{~nm}$ for the dehydrated samples (calcined at $673 \mathrm{~K}$ before UV-Vis spectra recording). The absorption edge energies of the UV-Vis spectra were determined by finding the intercept of the straight line in the low-energy rise of a plot of $\left[\mathrm{F}\left(\mathrm{R}_{\infty}\right) \mathrm{h} \nu\right]^{1 / 2}$ against $\mathrm{h} \nu$ and, where $F\left(R_{\infty}\right)$ is a Kubelka-Munk function, $h \nu$ is the energy of the incident photon [17].

The nature of acid sites was investigated using pyridine as the probe molecule. All the samples were pressed into the form of self-supporting discs (ca. $5 \mathrm{mg} / \mathrm{cm}^{2}$ ) and subjected to heating in a quartz IR cell at $623 \mathrm{~K}$ under vacuum for $1 \mathrm{~h}$. Excess pyridine vapour sufficient to neutralize all acid sites was adsorbed at $443 \mathrm{~K}$ under static conditions, followed by an evacuation at the same temperature to remove the gaseous and physisorbed pyridine molecules, which had been tracked by the recording of spectra. Subsequently, the 
FTIR spectrum was taken at $403 \mathrm{~K}$. The band intensities in this spectrum were used to calculate the total concentration of Brønsted and Lewis sites. The total concentration of Brønsted and Lewis sites was calculated using the intensities of the $1545 \mathrm{~cm}^{-1}$ band of pyridinium ions $\left(\mathrm{Py}^{+}\right)$and the $1450 \mathrm{~cm}^{-1}$ band of pyridine coordinatively bonded to Lewis sites $(\mathrm{PyL})$, respectively, by applying their respective extinction coefficients [18]. The acid strength distribution was determined on the basis of pyridine desorption studies at elevated temperatures under high vacuum conditions. The conservation of the $1545 \mathrm{~cm}^{-1}$ (Brønsted sites) and $1450 \mathrm{~cm}^{-1}$ (Lewis sites) bands under the desorption treatment at elevated temperature (503 $\mathrm{K}$ ) was taken as a measure of the strength of the acid sites $\left(\mathrm{A}_{\mathrm{des}} / \mathrm{A}_{0}\right)$. All the spectra were recorded with a resolution of $2 \mathrm{~cm}^{-1}$ using a Bruker Vertex 70 spectrometer equipped with an MCT detector.

The microRaman measurements of dehydrated samples were performed with a Renishaw InVia dispersive spectrometer equipped with a CCD detector and integrated with a Leica DMLM confocal microscope. Prior to the measurements the catalyst had been dehydrated by evacuation at $673 \mathrm{~K}$ using a home-made cell. The $514 \mathrm{~nm}$ line of an argon ion laser was used as exciting light. The spectra were recorded at ambient conditions with a resolution of $2 \mathrm{~cm}^{-1}$. The Raman scattered light was collected with a 50× Olympus objective in the spectral range of $100-1500 \mathrm{~cm}^{-1}$.

Surface morphology and structural properties of the MCF support, as well as vanadium doped samples, were studied by both transmission electron microscopy (TEM, Hitachi HT7700 operating at $100 \mathrm{kV}$ ) and scanning electron microscopy (SEM, Hitachi SU3500). For TEM analysis the specimens were prepared by dry dispersing of the catalyst powder on standard copper grids coated with carbon film. Transmission electron microscope (TEM) images were also used for elemental analysis with the help of energy dispersive X-ray spectroscopy TEM/EDS.

\subsection{Reaction Test}

Catalytic performance tests were made under atmospheric pressure in a glass reactor (10 $\mathrm{mm}$ i.d.) using a continuous-flow system in the temperature range of 593-673 K. A mixture of propene, $\mathrm{N}_{2} \mathrm{O}$, and helium as diluent was passed through a fixed bed containing the catalyst samples. Before the reaction run, $0.50 \mathrm{~g}$ of the catalyst (sieve fraction of $0.3-0.5 \mathrm{~mm}$ ) was pre-treated in a helium flow $\left(12.5 \mathrm{~cm}^{3} / \mathrm{min}\right)$ at $673 \mathrm{~K}$ for $30 \mathrm{~min}$. The feed gas composition of propene and $\mathrm{N}_{2} \mathrm{O}$ (propene $99.5 \mathrm{vol} \%$ from Linde and $\mathrm{N}_{2} \mathrm{O}: 99.995 \mathrm{vol} \%$ from Messer) diluted with helium ( $\geq 99.9999$ vol\%, Linde) was introduced into the reactor to start the reaction after the catalyst bed had reached the desired reaction temperature. The ratio of the reaction gas components $\mathrm{C}_{3} \mathrm{H}_{6}, \mathrm{~N}_{2} \mathrm{O}$, and $\mathrm{He}$ was equal to 1:15: $\mathrm{x}$, where $x=62,40,24$, and $12.5 \mathrm{~cm}^{3} / \mathrm{min}$, related to different contact times (1.5, 2.1, 3.0 and 4.2, respectively). The flow of the gases was precisely controlled by mass flow controllers (MFC Brooks).

The composition of the reactor outlet was analysed by on-line gas chromatography. The feed and the products were analysed by two GCs equipped with TCD (Porapak QS packed column) and FID (WCOT Fused Silica capillary column) detectors with automatic injection systems. The valves and the lines connecting the output of the reactor with the gas chromatographs were heated to $393 \mathrm{~K}$ to prevent condensation of the products. The results after $30 \mathrm{~min}$ on stream are presented and used for discussion, unless stated otherwise.

The catalytic activity calculation has been described elsewhere [19]. It was evaluated from the concentrations of the products detected (i.e., propene oxide, acrolein, acetone, propionaldehyde, $\mathrm{CO}$, and $\mathrm{CO}_{2}$ ) and the remaining propene. TOF was evaluated on the basis of the amount of propene (in moles) transformed to propene oxide related to surface vanadium species (expressed in moles) per second [20]. The space-time yield (STY) of propene oxide was defined as the number of PO molecules produced at the reactor output per catalyst mass per hour.

\section{Results}

\subsection{Catalyst Characterization}

The surface area of MCF support was $676 \mathrm{~m}^{2} / \mathrm{g}$ and it decreased after vanadium incorporation to about $500 \mathrm{~m}^{2} / \mathrm{g}$ for the samples comprising $3 \mathrm{wt} \%$ of vanadium and to $443 \mathrm{~m}^{2} / \mathrm{g}$ for the samples with $5 \mathrm{wt} \%$ of vanadium (Table 1). Both non modified and vanadium modified samples show the adsorption/desorption isotherms of IV type, typical for a three-dimensional structure with $\mathrm{H} 1$ shape, with a steep hysteresis curve recorded at a high $\mathrm{p} / \mathrm{p}_{0}$ value $(0.6-0.7)$ (Fig. 1A). On the basis of adsorption and desorption branches of isotherms, the cell size $\left(\mathrm{D}_{\mathrm{c}}\right)$ and the window size $\left(D_{w}\right)$ characteristic for MCF support and also 3V/MCF and $5 \mathrm{~V} / \mathrm{MCF}$ were calculated according to BJH theory. Their values are presented in Table 1.

XRD patterns of the synthesised support (MCF) and the related vanadium catalysts recorded in the range of low diffraction angels $0.3-6^{\circ}$ of $2 \theta$ showed signals characteristic of regular wide mesopores (Fig. 1B), indicating the preservation of support structure after the introduction of vanadium precursors.

FT-IR spectra recorded for bare MCF and vanadium modified MCF support indicate that vanadium species interact with the hydroxyl groups characterized with an IR band at $3735 \mathrm{~cm}^{-1}$, which are considered as non-acidic. As a result 
Table 1 Properties of vanadium free and vanadium modified MCF

\begin{tabular}{lllllc}
\hline Catalysts & $\begin{array}{l}\text { Vanadium concentra- } \\
\text { tion }(\mathrm{wt} \%)^{\mathrm{a}}\end{array}$ & $\mathrm{S}_{\mathrm{BET}}\left(\mathrm{m}^{2} / \mathrm{g}\right)$ & $\mathrm{D}_{\mathrm{c}}(\mathrm{nm})^{\mathrm{b}}$ & $\mathrm{D}_{\mathrm{w}}(\mathrm{nm})^{\mathrm{c}}$ & $\begin{array}{c}\text { Surface density } \\
\left(\mathrm{V} \text { atoms } / \mathrm{nm}^{2}\right)\end{array}$ \\
\hline $\mathrm{MCF}$ & - & 676 & 20.3 & 13.7 & - \\
$3 \mathrm{~V} / \mathrm{MCF}$ & 2.8 & 502 & 18.2 & 12.0 & 0.66 \\
$5 \mathrm{~V} / \mathrm{MCF}$ & 4.9 & 443 & 17.5 & 10.0 & 1.30 \\
\hline
\end{tabular}

${ }^{\mathrm{a}} \mathrm{V}$ content by ICP

${ }^{\mathrm{b}}$ Cell diameter $\left(\mathrm{D}_{\mathrm{c}}\right)$ obtained from nitrogen sorption

${ }^{c}$ Window diameter $\left(\mathrm{D}_{\mathrm{w}}\right)$ obtained from nitrogen sorption
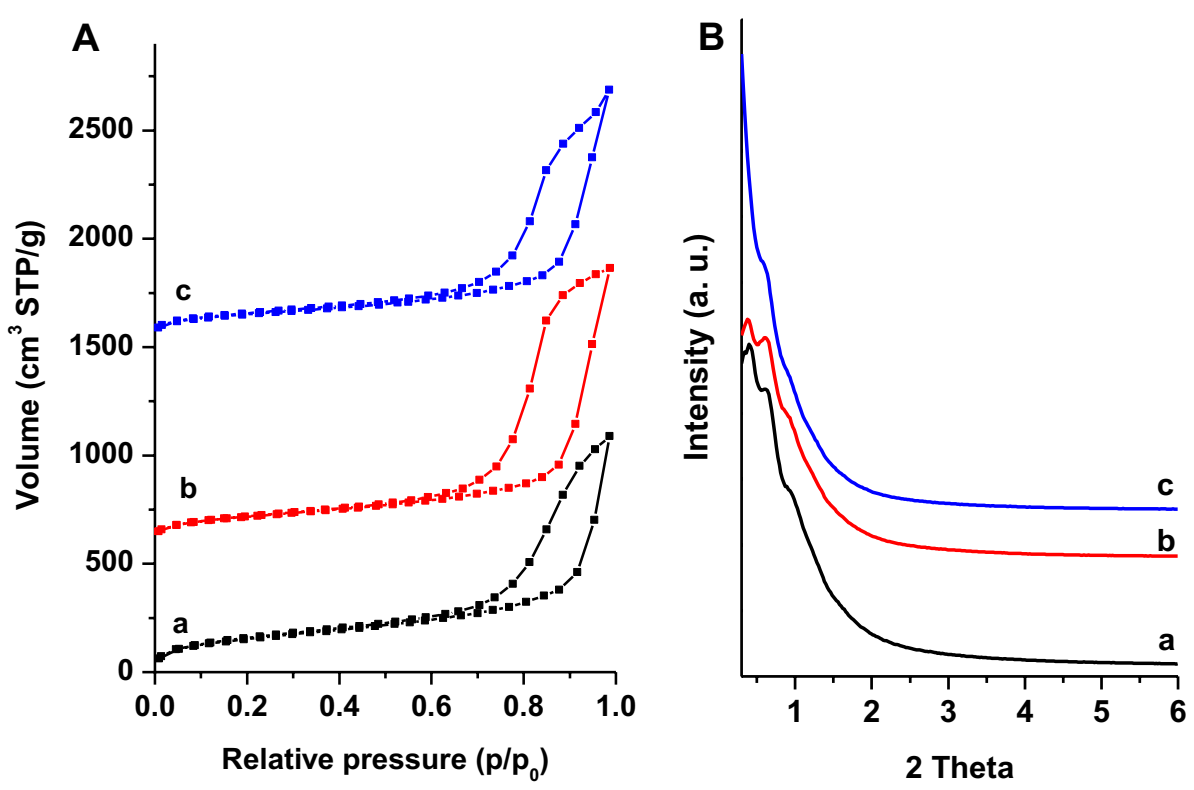

Fig. 1 Nitrogen adsorption/ desorption isotherms (A) and XRD patterns at low diffraction angles ( $2 \theta$ in the range of $\left.0.3^{\circ}-6^{\circ}\right)(\mathbf{B})$ on parent MCF (a) and vanadium modified $3 \mathrm{~V} /$ $\operatorname{MCF}(b)$, and 5V/MCF (c)

Fig. 2 The IR spectra in the range of $\mathrm{OH}$ groups (A) and IR spectra of pyridine adsorbed (B) for parent $\mathrm{MCF}(a)$ and vanadium modified $3 \mathrm{~V} / \mathrm{MCF}$ (b), and 5V/MCF (c)

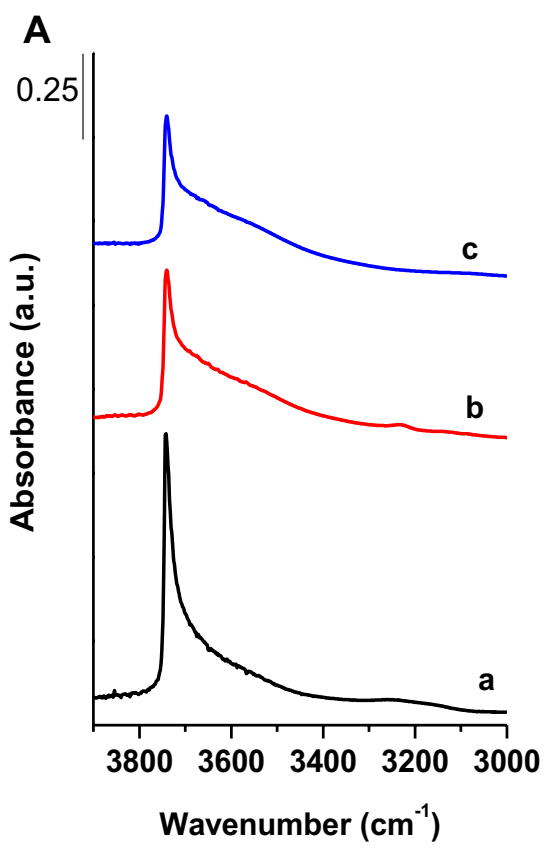


of the introduction of vanadium precursors the intensity of these bands decreases (Fig. 2A). FT-IR spectra of adsorbed pyridine show that non modified MCF support does not possess any Brønsted acidity and only extremely weak Lewis acidic sites were detected. Introduction of vanadium species results in the formation of both Brønsted and Lewis acidic sites (Fig. 2B; Table 2). The number of acidic sites increases with the amount of vanadium introduced. However, the number of Brønsted acidic sites is still low and it is comparable to the acidity of zeolites with an $\mathrm{Si} / \mathrm{Al}$ ratio equal to 500 . The number of Lewis acid sites is also low and is clearly lower than the related values for aluminosilicate mesoporous materials with an $\mathrm{Si} / \mathrm{Al}$ ratio from 1 to 10 , calculated in a similar way [21]. On the other hand, the strength of both Brønsted and Lewis acid sites of vanadium modified MCF material is low and is comparable to that recorded for mesoporous aluminosilicates with an $\mathrm{Si} / \mathrm{Al}$ equal to 10 (Table 2).

The TEM images recorded for MCF and vanadium catalysts $3 \mathrm{~V} / \mathrm{MCF}$ and $5 \mathrm{~V} / \mathrm{MCF}$ reveal the presence of cylindrical pores of about $20 \mathrm{~nm}$ diameter with a disordered arrangement without any channels (Fig. 3B, D, F). The introduction of vanadium modifier does not influence the MCF structure and no crystalline $\mathrm{V}_{2} \mathrm{O}_{5}$ particles have been observed. TEM/ EDS mapping (Fig. 1S) indicates a homogeneous distribution of vanadium species on the support surface.

SEM micrographs of MCF support show the presence of mostly spherical silica particles, of about 1-3 $\mu \mathrm{m}$ in size (Fig. 3A, C, E) [22]. The introduction of a vanadium precursor does not change the size and shape of $\mathrm{MCF}$ agglomerates.

Raman spectra recorded for dehydrated 3V/MCF catalyst indicate the bands at about 270-280, 415, 486, 699, $820,930,1034 \mathrm{~cm}^{-1}$, and a weak band at about $1070 \mathrm{~cm}^{-1}$ (Fig. 4). The Raman band at $1035 \mathrm{~cm}^{-1}$ is characteristic of the stretching frequencies of a terminal $\mathrm{V}=\mathrm{O}$ bond attributed to the presence of isolated, tetrahedrally coordinated $\mathrm{VO}_{4}$ species [23, 24]. It confirms the high dispersion of supported vanadium species (in accordance with TEM/EDS pictures). This suggestion is also in agreement with DR UV-Vis spectra, which point to the high dispersion of vanadium species (Fig. 5A, B). It shows that mainly isolated tetrahedral

Table 2 The concentration and the strength of Brønsted (B) and Lewis (L) sites measured by pyridine

\begin{tabular}{|c|c|c|c|c|}
\hline \multirow[t]{2}{*}{ Sample } & \multicolumn{2}{|c|}{$\begin{array}{l}\text { Concen- } \\
\text { tration } \\
\text { of acid } \\
\text { sites } \\
(\mu \mathrm{mol} \\
\left.\mathrm{g}^{-1}\right)\end{array}$} & \multicolumn{2}{|c|}{$\begin{array}{l}\text { Strength } \\
\text { of acid } \\
\text { sites } \\
\left(\mathrm{A}_{\text {des. }} / \mathrm{A}_{0}\right)\end{array}$} \\
\hline & B & $\mathrm{L}$ & B & $\mathrm{L}$ \\
\hline $\mathrm{MCF}$ & 0 & 55 & 0 & 0 \\
\hline $3 \mathrm{~V} / \mathrm{MCF}$ & 15 & 160 & 0.35 & 0.80 \\
\hline $5 \mathrm{~V} / \mathrm{MCF}$ & 30 & 180 & 0.55 & 0.80 \\
\hline
\end{tabular}

vanadium species are formed as a result of a small amount of vanadium precursor impregnation on MCF support. However, the increase in vanadium concentration (from 3 to $5 \mathrm{wt} \%$ ) results in the appearance of a weak band at about $1000 \mathrm{~cm}^{-1}$ indicating the formation of a small amount of $\mathrm{V}_{2} \mathrm{O}_{5}$ crystals. A similar observation, showing the formation of vanadia in V/MCF samples with a vanadium concentration of about $5 \mathrm{wt} \%$, prepared by means of impregnation, has been reported by Piumetti et al. [25] and also by Liu et al. [26]. According to Wang and Wachs [23] and also to Keller et al. [24] the bands in the range of 200-300 and $500-800 \mathrm{~cm}^{-1}$ should be attributed to $\mathrm{V}-\mathrm{O}-\mathrm{V}$ vibrations, which indicate the presence of dimeric or polymeric tetrahedral vanadium species. Additionally, Raman spectra recorded for all the studied samples revealed a broad band at about $920-930 \mathrm{~cm}^{-1}$ and a weak band at $1070 \mathrm{~cm}^{-1}$. These bands, according to Nguyen et al. [27], Magg et al. [28], and also to Keller et al. [24] should be attributed to V-O-Si out-of-phase vibrations and they confirm a high distribution of vanadium species.

Additional information about the structure of vanadium surface species was obtained on the basis of UV-Vis spectra. In order to distinguish between different $\mathrm{VO}_{\mathrm{x}}$ species, the presented spectra have been deconvoluted into several Gaussian curves. For the dehydrated samples of V/MCF catalysts, the spectra could be deconvoluted into three individual components.

The maxima of the presented spectra were located in the range of 250-360 nm (Fig. 5A, B). UV-Vis spectra of 3V/ MCF and 5V/MCF samples recorded under dehydrated conditions showed the strongest band at about $250 \mathrm{~nm}$, which according to earlier literature is attributed to charge transfer transitions of isolated $\mathrm{V}^{5+}$ species in tetrahedral coordination $[29,30]$. The weaker bands with maxima located at about 300 and $350 \mathrm{~nm}$ point to the presence of a small amount of polymerized vanadium occurring in a square-piramidal coordination. The UV-Vis spectra are in agreement with the results of Raman spectra analysis indicating the presence of mainly isolated vanadium species in tetrahedral coordination. The high vanadium species dispersion can be also derived from the edge energy calculated for V/MCF samples using Tauc law [17]. The edge energy was higher than 2.5 and it was equal to 3.8 and 3.6 for $3 \mathrm{~V} / \mathrm{MCF}$ and $5 \mathrm{~V} / \mathrm{MCF}$ samples, respectively (Fig. 2S).

\subsection{Catalytic Tests in Propene Epoxidation}

The activities of the vanadium catalysts prepared by impregnation of $\mathrm{VOSO}_{4}$ on mesocellular siliceous foams were explored under steady-state conditions at 593-673 K with a constant space velocity (GHSV $-3.4 \mathrm{~L} \mathrm{~g}^{-1} \mathrm{~h}^{-1}$ ) and propene $/ \mathrm{N}_{2} \mathrm{O} /$ helium ratio $(1: 15: 12.5)$. The remarkable propene epoxidation activity over V/MCF catalysts is indicated in 

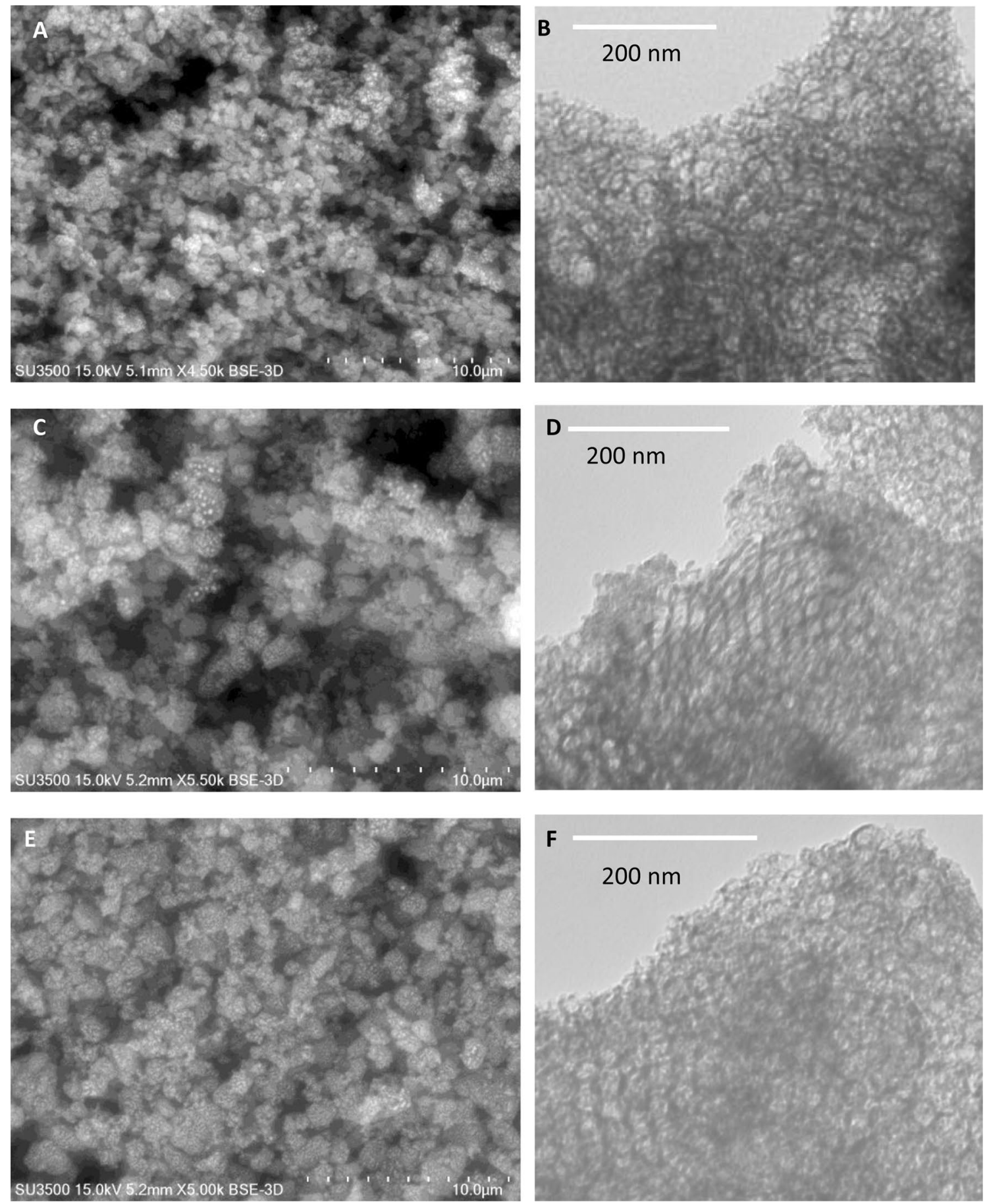

Fig. 3 Representative SEM (A, C, E) and TEM (B, D, F) images of parent MCF (A, B), and vanadium modified 3V/MCF (C, D), and 5V/MCF $(\mathbf{E}, \mathbf{F})$

Fig. 6. For comparison, the catalytic results of V-containing mesoporous SBA-3, MCM-41, and SBA-15 catalysts, previously studied by our group $[15,16]$, are also presented in Fig. 6.

Propene oxide, propionaldehyde, acetone, acrolein, and $\mathrm{CO}_{\mathrm{x}}\left(\mathrm{CO}\right.$ and $\left.\mathrm{CO}_{2}\right)$ were the main reaction products formed on the studied catalysts. With a similar vanadium concentration, the V/MCF sample exhibited much higher $\mathrm{C}_{3} \mathrm{H}_{6}$ conversion and propene oxide yield, and also clearly lower total oxidation than the V/SBA-3, V/SBA-15, and V/ MCM-41 samples. The highest propene oxide productivity, expressed as STY of PO, and calculated for vanadium 


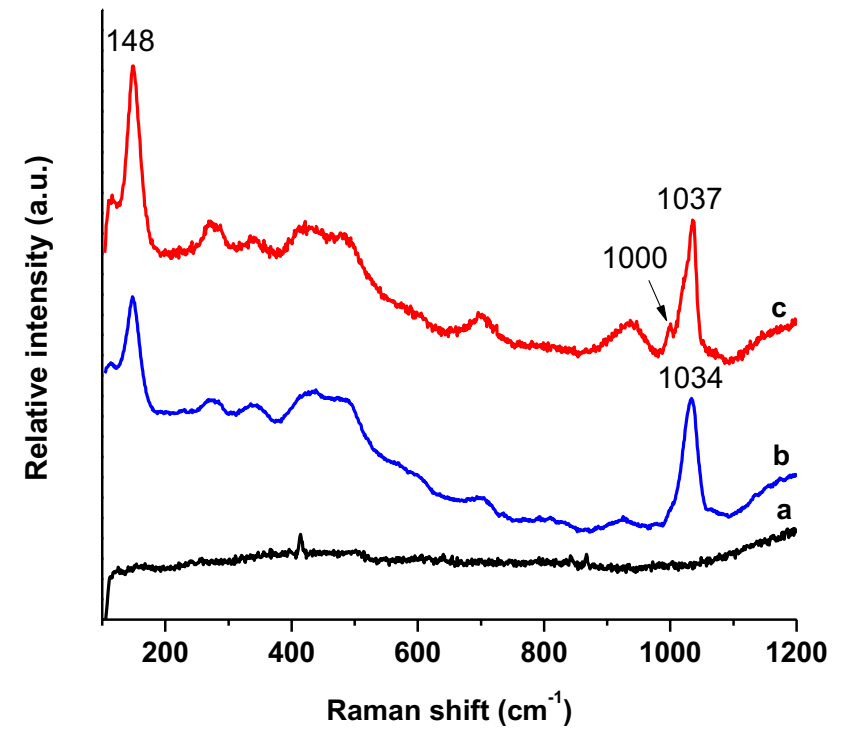

Fig. 4 Raman spectra of parent $\mathrm{MCF}(a)$ and vanadium modified $3 \mathrm{~V} /$ $\mathrm{MCF}(b)$, and 5V/MCF $(c)$
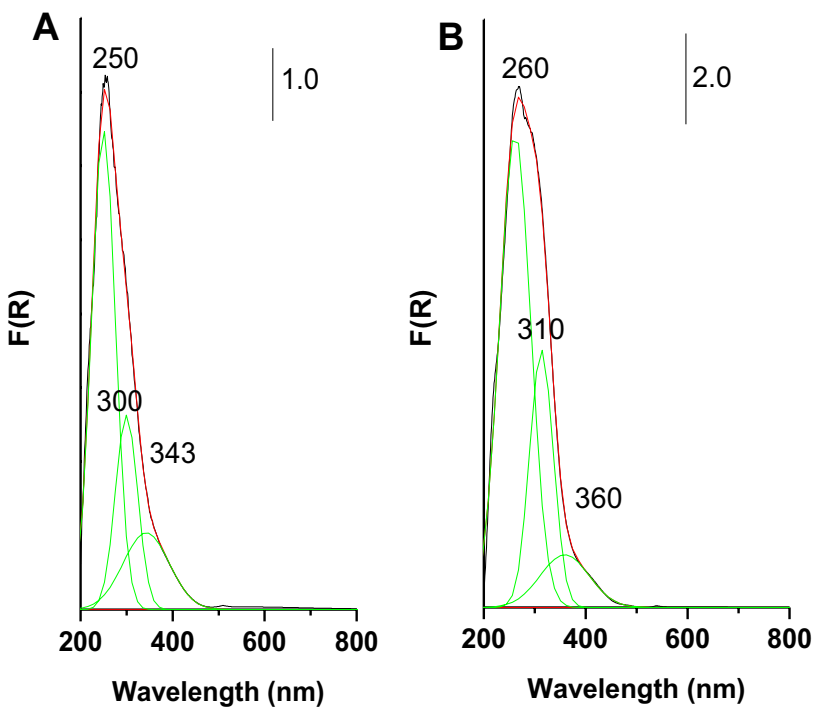

Fig. 5 Deconvoluted UV-Vis reflectance spectra of dehydrated vanadium modified MCF: samples 3V/MCF (A) and 5V/MCF (B)

modified mesoporous materials of 2D structure, has been obtained for $5 \mathrm{~V} / \mathrm{MCM}-41\left(9.5 \mathrm{~g}_{\mathrm{PO}} / \mathrm{kg}_{\mathrm{cat}} / \mathrm{h}\right)$. For $5 \mathrm{~V} / \mathrm{MCF}$ catalyst, PO productivity was much higher and reached almost $37 \mathrm{~g}_{\mathrm{PO}} / \mathrm{kg}_{\text {cat }} / \mathrm{h}$ (Fig. 7).

Not only propene conversion and selectivity to PO show better performance on V/MCF when compared to $2 \mathrm{D}$ silicas but also turnover frequency, indicating the exploitation of supported vanadium species, shows higher value when compare to V/SBA-3, V/SBA-15, and V/MCM-41 (Fig. 3S). This confirms the suggestion that the MCF with a large pore diameter and the interconnected $3 \mathrm{D}$ pore system is far
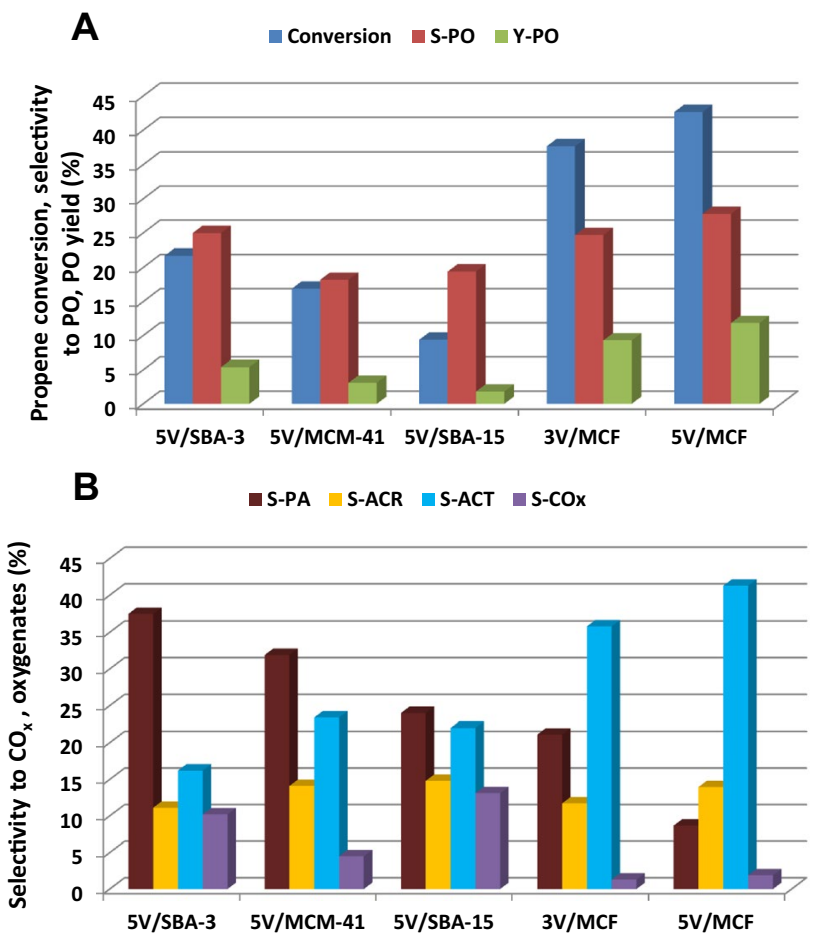

Fig. 6 Propene selective oxidation over vanadium modified 5V/SBA3, 5V/MCM-41, 5V/SBA-15, 3V/MCF, and 5V/MCF: (A) propene conversion, selectivity to propene oxide (PO), propene oxide yield, (B) selectivity to oxygen-bearing products (propionaldehyde (PA), acrolein $(\mathrm{ACR})$, acetone $\left.(\mathrm{ACT}), \mathrm{CO}_{\mathrm{x}},\left(\mathrm{CO}, \mathrm{CO}_{2}\right)\right)$; reaction temperature $653 \mathrm{~K}$

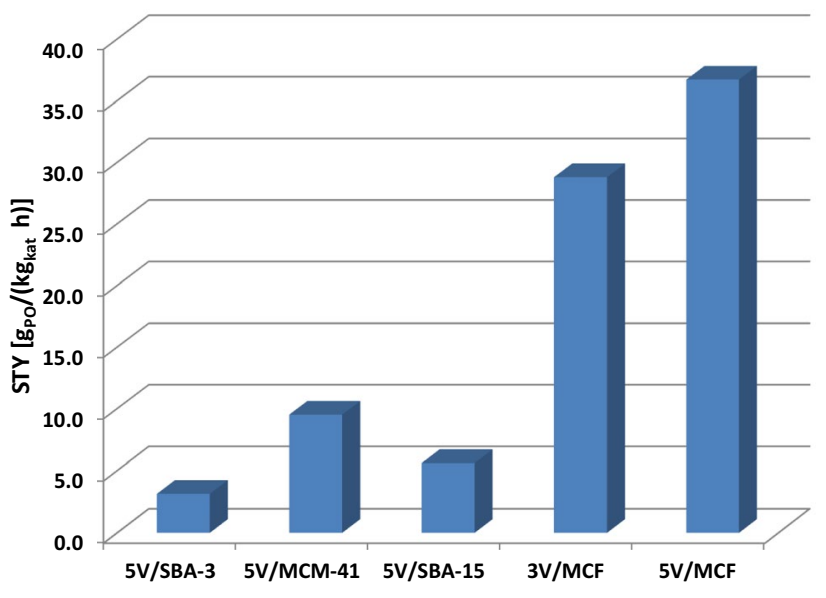

Fig. 7 Space time yield of propene oxide over vanadium modified mesoporous silica; reaction temperature $653 \mathrm{~K}$

superior to two-dimensional hexagonally ordered SBA-3, SBA-15, and MCM-41 as supports.

Figure 8 plots the epoxidation of propene on the V/ MCF catalyst as a function of the reaction temperature. It has been shown that with an increase in reaction temperature the propene conversion grows significantly, with 

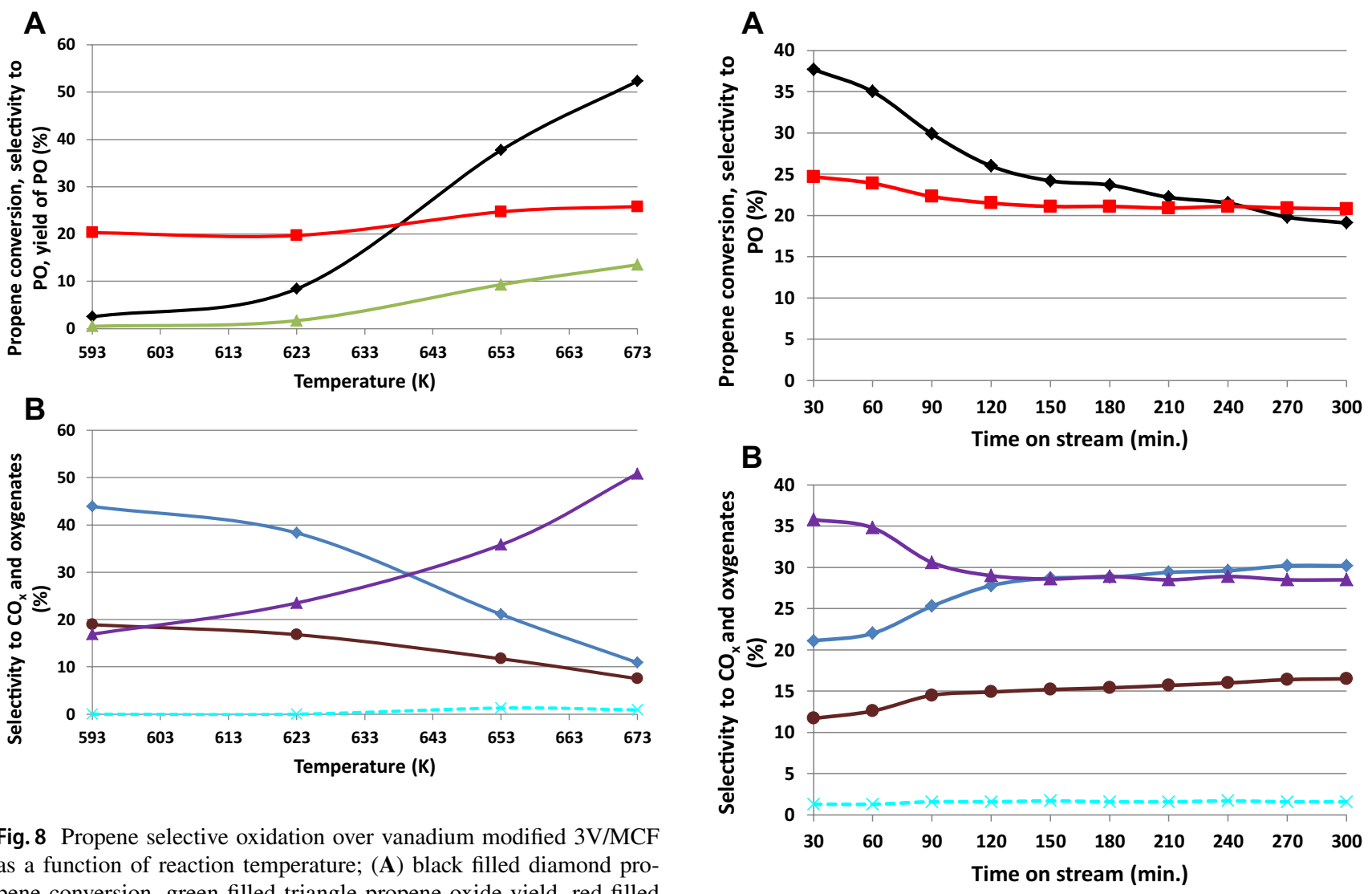

Fig. 8 Propene selective oxidation over vanadium modified 3V/MCF as a function of reaction temperature; (A) black filled diamond propene conversion, green filled triangle propene oxide yield, red filled square selectivity to propene oxide, $(\mathbf{B})$ selectivity to: blue filled diamond propionaldehyde, brown filled circle acrolein, purple filled triangle acetone, and blue multiplication sign $\mathrm{CO}_{\mathrm{x}}$ (dashed line)

a simultaneous enhancement of selectivity to PO of about $30 \%$ (from 20 to $26 \%$ ) (Fig. 8A). With an increase in the reaction temperature, a clear decrease in the selectivity to propionaldehyde and to acrolein with a concurrent increase in the selectivity to acetone was also observed (Fig. 8B). Independent of vanadium concentration in catalysts supported on MCF material, the total oxidation was very low and selectivity to $\mathrm{CO}_{\mathrm{x}}$ did not exceed $3 \%$ in the whole range of the applied reaction temperatures.

The catalytic performance of V/MCF materials was also tested with time on stream. Propene conversion decreases slowly with time on stream (during the first $2 \mathrm{~h}$ ), while selectivity to oxygenates changes slightly (Fig. 9), which indicates the high stability of vanadium supported MCF catalysts.

To discuss the probable reaction path of propene oxidation the additional catalytic experiments at different contact times $(1.5,2.1,3.0$, and $4.2 \mathrm{~s})$ were performed. Prolongation of contact time results in higher propene conversion and also in some increase in selectivity to PO and clear decrease in selectivity to ACR (Fig. 4S).

Fig. 9 Propene selective oxidation on 3V/MCF performed at $653 \mathrm{~K}$ as a function of time on stream: (A) black filled diamond propene conversion, red filled square selectivity to propene oxide; (B) selectivity to oxygenates: blue filled diamond propionaldehyde, brown filled circle acrolein, purple filled triangle acetone, and blue multiplication sign $\mathrm{CO}_{\mathrm{x}}$, (dashed line)

Selectivity to $\mathrm{CO}_{\mathrm{x}}$ and to PA decreases with lowering of propene conversion.

\section{Discussion}

Spectroscopic characterization of V/MCF catalysts using Raman and UV-Vis spectroscopy, revealed the presence of various $\mathrm{VO}_{\mathrm{x}}$ surface structures (monomers, polymers, and crystals), however, isolated tetrahedral $\mathrm{VO}_{4}$ species predominated (Figs. 4, 5). Previous investigations concerning the use of vanadia-based silica supported catalysts for propene epoxidation have shown that various parameters of the catalysts, including aggregation state and reducibility of vanadium species, acid/base properties, and vanadium content, need to be considered to account for the catalytic behavior noted for the selective oxidation of propene $[15,19]$. It has been shown that catalysts with high vanadium dispersion show better performance in a number of oxidation reactions such as propane oxydehydrogenation [31], methanol partial 
oxidation [32], and also in selective propene oxidation [15, $19,33]$. The presence of an isolated tetrahedral vanadium oxide species is essential as it facilitates the interaction with $-\mathrm{N}^{\delta-}=\mathrm{N}^{\delta+}=\mathrm{O}$ species, a mezomeric form of $\mathrm{N}_{2} \mathrm{O}$, with the formation of mildly electrophilic oxygen forms. Weakly electrophilic oxygen interacts with a $\mathrm{C}=\mathrm{C}$ bond of propene with the subsequent formation of mainly PO, although PA and ACT may also be products of this interaction [8]. The high contribution of PA and ACT in reaction products is also a result of the high reactivity of $\mathrm{PO}$, which brings about further transformation.

The vanadium-supported catalysts, obtained by a simple impregnation of an aqueous solution of $\mathrm{VOSO}_{4}$ on $\mathrm{MCF}$ mesoporous material, characterised by high vanadium distribution, appeared to be highly effective in propene epoxidation at temperatures below $673 \mathrm{~K}$, offering propene oxide yields much higher than those provided by previously studied vanadium containing catalysts $[14,15,19]$ as presented in Fig. 6. Interestingly, some specific changes in selectivity to oxygenate by-products have also been noted. Distinctly higher selectivity towards acetone with vanadium concentration increase and lowering in selectivity to propionaldehyde was recorded. Analysis of acidity of the studied catalysts seems to deliver some explanation. According to Annanieva et al. [9] the presence of relatively strong acidic sites (both Brönstedt and Lewis) results in the predominance of propionaldehyde as a product of $\mathrm{PO}$ isomerization. It has been found in an earlier study [15] that 5V/SBA-3 shows the highest acidity among the studied catalysts, while the acidity of $5 \mathrm{~V} / \mathrm{SBA}-15,5 \mathrm{~V} / \mathrm{MCM}-41$, and $5 \mathrm{~V} / \mathrm{MCF}$ is successively lower. Consequently, the amount of propionaldehyde, formed as a result of PO isomerization over catalysts characterized by lower acidity, decreases. This may explain the changes in PA and ACT contribution in products of propene oxidation recorded on different catalysts.

Polymeric vanadium species, observed for samples with higher vanadium concentration, could favour undesired combustion reaction pathways, leading to the formation of carbon oxides and also high molecular products. V/MCF catalysts were characterized by a relatively high selectivity to propene oxide, comparable with those observed for previously reported V/SBA-3, V/SBA-15, and V/MCM-41 catalysts, where the predominance of isolated vanadium species was also confirmed. Nevertheless, vanadium supported mesocellular silica foams were characterized by much higher propene conversion when compared to vanadium-supported mesoporous silicas of $2 \mathrm{D}$ structures, which results in a higher PO yield and a lower contribution of carbon oxides on V/MCF catalysts.

Thömmes et al. [32] studying iron supported catalysts for propene epoxidation indicated that because of the very high reactivity of PO the selectivity to this main product is limited and it was observed that the higher the propene conversion was the lower the selectivity to PO. Conversly, when vanadium catalysts were prepared over MCF silica of $3 \mathrm{D}$ structure, an increase in the reaction temperature resulted not only in the growth of propene conversion but also in higher selectivity to PO (Fig. 8). This may be explained by the specific structure of MCF support. MCF is characterized by the presence of spherical cells of about $20 \mathrm{~nm}$ diameter interconnected with windows (of a diameter of about $10 \mathrm{~nm}$ ) forming an open and easily accessible structure (Fig. 3). Thanks to the open structure of the support, vanadium precursors may be spread uniformly on the surface, as indicated in Raman spectra (Fig. 4) and also in TEM/EDS mappins images (Fig. 1S), which results in the formation of isolated monomeric vanadium species with $\mathrm{V}-\mathrm{O}-\mathrm{Si}$ bonds, active for propene epoxidation. The open structure of the V/MCF system also has an influence on the shortening of the way necessary to release the products from the inner space. It brings about a shortened contact of the reactive propene oxide molecule with catalytic sites and limits its further transformation. Very low selectivity to $\mathrm{CO}_{\mathrm{x}}$, at relatively high propene conversion ( $53 \%$ at $673 \mathrm{~K}$ ) also seems to result from the easy release of oxygenates from the catalysts inner space (Fig. 8).

It has been shown that increase in the reaction temperature results not only in higher propene conversion but also in some increse in PO selectivity. However, even though the yield of PO exceeded 10\% (reaching 13.5\%), oxygenates such as PA, ACT and ACR constitute the majority of oxidation products. Analysis of relationship of selectivity to specific oxidation products versus propene conversion (Fig. 4S) indicates that selectivity to oxygenates (propene oxide, acrolein and acetone) extrapolated to zero value of propene conversion show $0.26,0.31$, and 0.33 values, respectively. These results suggest that PO, ACR, and ACT are formed mainly directly form propene. Selectivity to PA decreases with propene conversion lowering and at propene conversion extrapolated to zero it shows a value of about 0.08 . It suggests that PA may be formed both as a primary product from propene oxidation and also as an effect of PO transformation. Selectivity of $\mathrm{CO}_{\mathrm{x}}$ decreased to near zero value when propene conversion was extrapolated to zero, which indicates that $\mathrm{CO}_{\mathrm{x}}$ is both a primary product of propene oxidation and the secondary product resulting from consecutive oxidation of propene oxide and other oxygenates. According to Liu et al. [33], propene oxide characterised by relatively high reactivity undergoes isomerisation to propionaldehyde and acetone. In the presented results acetone seems to be mainly a primary product of propene oxidation, although formation of some ACT as a result of PO isomerization cannot be excluded. According to Lifshitz and Tamburu [34] the formation of PA and ACT as a result of PO isomerization is a simple process involving $\mathrm{C}-\mathrm{O}$ rapture and hydrogen shift. However, according to Thömmas et al. [35] a very high rate 
of PA conversion, especially in the presence of $\mathrm{N}_{2} \mathrm{O}$, results in a lowering of the PA contribution in the oxidation product. Taking into account the high concentration of the active centers on $\mathrm{V} / \mathrm{MCF}$ catalysts it is possible to explain the low selectivity to PA in propene oxidation recorded on the studied samples, especially with higher vanadium concentration.

It has also been shown by $\mathrm{Li}$ and Shen [36] that the formation of acetone by means of propene oxidation over supported vanadium catalysts depends both on vanadium species dispersion and also on the number and strength of Brønsted acids. The above mentioned authors indicate that propene interacts with $-\mathrm{V}-\mathrm{O}-\mathrm{H}$ species, which are the Brønsted acid sites, with the following formation of isopropoxy species $\left(-\mathrm{O}-\mathrm{CH}\left(\mathrm{CH}_{3}\right)_{2}\right)$. The adsorbed isopropoxy species are transformed to acetone. Acetone may be easily adsorbed on the present Lewis acid sites. Considering that the studied catalysts (V/MCF) are characterized by their low number and the very low strength of Lewis acids (Table 2), acetone is easily desorbed and its further transformation is limited. This may explain the very high selectivity to acetone with temperature increase (Fig. 8B) and also clarify the different contribution of propionaldehyde and acetone depending on differing amounts of vanadium in catalysts.

Turnover frequency (TOF), defined as $\mathrm{mol}_{\mathrm{PO}} \mathrm{mol}_{\mathrm{V}}{ }^{-1}$ $\mathrm{s}^{-1}$, indicating the exploitation of supported vanadium species, was also used for estimation of V/MCF catalyst activity. TOF calculated for V/MCF catalsyst revealed a higher value when compared to vanadium catalysts supported on mesoporous SBA-3, SBA-15, and MCM-41 (Fig. 3S). This confirms the high availability of vanadium active species. A slightly lower TOF value calculated for $5 / \mathrm{MCF}$ when compared to $3 \mathrm{~V} / \mathrm{MCF}$ is in accrdance with the results of Raman and UV-Vis spectrscopies indicating a small amonut of polymeric vanadium species on the catalyst with higher vanadium concentration.

These results indicate that although the creation of active vanadium species is a prerequisite for gas-phase selective propene epoxidation, it does not completely account for the observed changes in activity and that the molecular transport properties of the catalyst must be also taken into account.

\section{Conclusions}

The presented study has demonstrated that MCF material with its unique textural structure is an attractive support applicable for the fabrication of promising V/MCF catalysts that are highly active in propene epoxidation. Raman and UV-Vis spectra indicated that MCF support allows better vanadium species dispersion to be obtained when compared to mesoporous silicas of 2D structure. A comparison of vanadium modified mesocellular silica foams with previously studied V/SBA-15, V/MCM-41, and V/SBA-3 catalysts demonstrates the superior performance of the V/ MCF system in propene epoxidation. It has been shown that a high concentration of isolated $\mathrm{V}$ species easily accessible to the reactants is readily achievable on the surface of the MCF support. Moreover, a much lower acidity of the surface acid sites of V/MCF catalysts limits the transformation of primary products. The superior performance of the V/MCF catalysts in propene epoxidation has been attributed to the well-defined 3D mesopore systems leading to favourable conditions for internal mass transfer thanks to an open and easily accessible structure.

Acknowledgements This work was supported by the National Science Centre, Poland, Grant No. 2016/23/B/ST5/00615.

Open Access This article is distributed under the terms of the Creative Commons Attribution 4.0 International License (http://creativeco mmons.org/licenses/by/4.0/), which permits unrestricted use, distribution, and reproduction in any medium, provided you give appropriate credit to the original author(s) and the source, provide a link to the Creative Commons license, and indicate if changes were made.

\section{References}

1. Tullo AH (2004) Chem Eng News 82:15

2. Nijhuis TA, Makkee M, Moulijn JA, Weckhuysen BM (2006) Ind Eng Chem Res 45:3447

3. Kalyoncu S, Düzenli D, Onal I, Seubsai A, Noon D, Senkan S, Say Z, Vovk EI, Ozensoy E (2015) Catal Lett 145:596

4. Oyama ST (2008) Mechanisms in homogeneous and heterogeneous epoxidation, Chap. 1. Elsevier, Amsterdam

5. Parmon VN, Panov GI, Uriarte A, Noskov AS (2005) Catal Today 100:115

6. Held A, Kowalska J, Nowińska K (2006) Appl Catal B 64:201

7. Nowińska K, Wącław A, Izbińska A (2003) Appl Catal A 243:225

8. Duma V, Hönicke D (2000) J Catal 191:93

9. Ananieva E, Reitzmann A (2004) Chem Eng Sci 59:5509

10. Sobolev VI, Kharitonov AS, Paukshtis YeA, Panov GI (1993) J Mol Catal 84:117

11. Wącław A, Nowińska K, Schwieger W (2004) Appl Catal A 270:151

12. Kondratenko EV, Cherian M, Baerns M (2006) Catal Today 112:60

13. Kuśtrowski P, Segura Y, Chmielarz L, Surman J, Dziembaj R, Cool P, Vansant EF (2006) Catal Today 114:307

14. Held A, Kowalska-Kuś J, Łapiński A, Nowińska K (2013) J Catal 306:1

15. Held A, Kowalska-Kuś J, Nowińska K, Góra-Marek K (2017) J Catal 347:21

16. Kuśtrowski P, Chmielarz L, Surman J, Bidzińska E, Dziembaj R, Cool P, Vansant EF (2005) J Phys Chem A 109:9808

17. Liu Y-M, Cao Y, Yi N, Feng W-L, Dai W-L, Yan S-R, He H-Y, Fan K-N (2004) J Catal 224:417

18. Garg S, Soni K, Kumaran GM, Bal R, Gora-Marek K, Gupta JK, Sharma LD, Dhar GM (2009) Catal Today 141:125

19. Held A, Kowalska-Kuś J, Nowińska K (2012) Catal Commun 17:108

20. Lu J, Zhang X, Bravo-Suárez JJ, Bando KK, Fujitani T, Oyama ST (2007) J Catal 250:350 
21. Góra-Marek K, Derewiński M, Sarv P, Datka J (2005) Catal Today 101:131

22. Aktas O, Yasyerli S, Dogu G, Dogu T (2011) Mater Chem Phys 131:151

23. Kondratenko EV, Cherian M, Baerns M, Su D, Schlögl R, Wang X, Wachs IE (2005) J Catal 234:131

24. Keller DE, Visser T, Soulimani F, Koningsberger DC, Weckhuysen BM (2007) Vib Spectrosc 43:140

25. Piumetti M, Bonelli B, Massiani P, Millot Y, Dzwigaj S, Gaberova L, Armandi M, Garrone E (2011) Microporous Mesoporous Mater 142:45

26. Liu Y-M, Feng W-L, Li T-C, He H-Y, Dai W-L, Huang W, Cao Y, Fan K-N (2006) J Catal 239:125

27. Nguyen LD, Loridant S, Launay H, Pigamo A, Dubois JL, Millet JMM (2006) J Catal 237:38
28. Magg N, Immaraporn B, Giorgi JB, Schroeder T, Bäumer M, Döbler J, Wu Z, Kondratenko E, Cherian M, Baerns M, Stair PC, Sauer J, Freund H-J (2004) J Catal 226:88

29. Gao X, Bare SR, Weckhuysen BM, Wachs IE (1998) J Phys Chem B 102:10842

30. Mathieu M, Van Der Voort P, Weckhuysen BM, Rao RR, Catana G, Schoonheydt RA, Vansant EF (2001) J Phys Chem B 105:3393

31. Rozanska X, Fortrie R, Sauer J (2007) J Phys Chem C 111:6041

32. Du G, Lim S, Pinault M, Wang C, Fang F, Pfefferle L, Haller GL (2008) J Catal 253:74

33. Liu J, Mohamed F, Sauer J (2014) J Catal 317:75

34. Lifshitz A, Tamburu C (1994) J Phys Chem 98:1161

35. Thömmes T, Reitzmann A, Kraushaar-Czarnetzki B (2008) Chem Eng Sci 63:5304

36. Li M, Shen J (2002) J Catal 205:248 